NASA Technical Memorandum 100819

\title{
Microwave Response of an HEMT Photoconductor
}

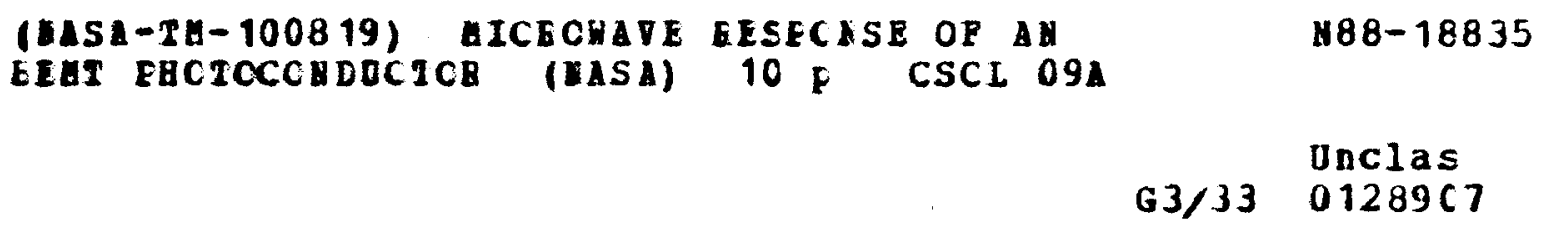

P.C. Claspy

Case Western Reserve University

Cleveland, Ohio

and

K.B. Bhasin

Lewis Research Center

Cleveland, Ohio

Prepared for

Optoelectronics and Laser Applications in Science and Engineering (O-E LASE '88)

sponsored by the Society of Photo-Optical Instrumentation Engineers

Los Angeles, California, January 10-15, 1988 
Microwave response of an HEMT photoconductor

\author{
P.C. Claspy \\ Department of Electrical Engineering and Applied Physics \\ Case Western Reserve University \\ Cleveland, Ohio 44016 \\ and
}

K.B. Bhasin

National Aeronautics and Space Administration

Lewis Research Center

Cleveland, Ohio 44135

\title{
ABSTRACT
}

Interdigitated photodetectors of various geometries have been fabricated on GaAlAs/GaAs heterostructure material. Optical response characteristics of these devices have been examined at both dc and microwave frequencies. The microwave response, at frequencies to $8 \mathrm{GHz}$, was studied by illuminating the devices with the output of an internally modulated GaAlAs diode laser. Results of these measurements are presented and compared with that of GaAs photoconductors.

\section{INTRODUCTION}

High frequency fiber optic links are being considered to provide interconnections among GaAs monolithic microwave integrated circuits (MMIC's) for RF feed, injection locking, phase control, and amplitude control in phased array antenna systems. The use of optical fibers instead of waveguides and coaxial cables for system interconnections offers reduction in weight, size, and crosstalk. 1 such links, however, require transmitters and receivers. For large arrays, discrete receivers bonded to GaAs MMIC's will add to the problem rather than providing the solution. Integrated optical receivers whose structure is compatible with GaAs MMIC's and which can be fabricated using MMIC fabrication techniques will make small size, single package elements possible. These optical receivers require photodetectors with interdigitated surface geometries to improve coupling efficiency and reduce alignment problems. Several photoconductors using GaAs MESFET structures have been demonstrated 2,3 and their performance in optical receivers has been evaluated. 4 Large gain-bandwidth photoconductors, based on heterostructures $5-7$ have also been produced, but the performance of these devices in microwave fiber optic links is not well characterized.

In this paper we discuss the design and fabrication of photoconductive detectors on GaAlAs/GaAs heterostructure material (HEMT). We also present the results of a study of the microwave performance of these devices and compare the results with those of a similar study of GaAs MESFET detectors.

\section{DETECTOR STRUCTURE AND FABRICATION}

An interdigitated electrode structure was chosen for the HEMT photoconductive detectors, as shown in Fig. 1. The active area of the devices is $50 \mu m$ square and the length of the ohmic contact fingers is $45 \mu \mathrm{m}$. Two different geometries, with contact spacings of 2.5 and $5 \mu \mathrm{m}$ respectively, were fabricated. The vertical structure of the HEMT material, which was grown by MBE techniques on semi-insulating GaAs substrate, is shown schematically in Fig. 2. Beginning at the substrate it consists of a 1.20 um undoped GaAs layer, a $40 \AA$ GaAlAs spacer, followed by a heavily doped $\left(1018 / \mathrm{cm}^{3}\right) 400 \AA$ GaAlAs 1 ayer, and finally a heavily doped GaAs layer to provide for ohmic contacts. Following a mesa etch the $\mathrm{Au} / \mathrm{Ge} / \mathrm{Ni}$ ohmic contacts were fabricated using a lift off technique. A gold layer thickness of 4000 \& was used to improve the current-carrying capability. Following a flash anneal of the electrodes the cap GaAs layer was removed from the open areas by etching. Finally, the devices were mounted on and ribbon bonded to a modified SMA end launcher of the type used for the transition from microstrip transmission line to microwave coaxial cable.

Three types of photodetectors fabricated on GaAs MESFET-type structures, with three different geometries and contact types, as shown in Fig. 3(a) to (c), were obtained from Honeywell Inc.'s Physical Sciences Center for comparison. The contacts on these devices are, respectively, Schottkey-Schottkey, Ohmic-Schottkey, and Ohmic-Ohmic. 


\section{EXPERIMENTAL ARRANGEMENTS}

Measurements of the response of the detectors to dc light were made using a Tektronix Curve Tracer with device illumination -provided through an incident light microscope. The microwave measurements were made using the system shown schematically in Fig. 4 . These measurements were limited to the 2 to $8 \mathrm{GHz}$ frequency range by the Avantek signal amplifier. To ensure that the measurements were not adversely affected by the instrumentation the sweep rate of the spectrum analyzer was set at 50 times that of the swept oscillator. The modulation linearity of both ortel, Inc. laser diodes used in these experiments was checked using a known high speed detector.

\section{EXPERIMENTAL RESULTS}

An I-V curve of the HEMT detector, a symmetric device, is shown in Fig. 5. The operation of this device is independent of bias polarity and the initial linear slope of the curve around the origin closely corresponds to the theoretical low field bulk resistance between the ohmic contacts, and is about $10 \Omega$. The high field saturation is caused by a combination of carrier velocity saturation and channel pinch-off. The slope, and therefore the detector resistance at dc, is seen to be a function of the bias, starting at a low value for small bias and smoothly increasing as the bias is increased. A responsivity of $4.4 \mathrm{~A} / \mathrm{W}$ was achieved at $800 \mathrm{~nm}$ wavelength.

Amplitude frequency response measurements of each of the MESFET-type devices and of the $5 \mu \mathrm{m}$ HEMT device over the frequency range of 2 to $8 \mathrm{GHz}$ were made using the system of Fig. 4. The former results are shown in Fig. 6 and the latter in Fig. 7 . A comparison of the two results shows that, while the slopes and 3 dB frequencies for the devices are different, the total response bandwidths of the $1 . \mu \mathrm{m}$ Ohmic-Ohmic MESFET detector and the $5 \mu \mathrm{m}$ HEMT detector are similar. This has encouraged us to fabricate a $1 \mu \mathrm{m}$ detector on the HEMT material. The electrode structure of this device is shown in Fig. B. Microwave characterization of this new detector is in progress and results will be reported in a future paper.

\section{CONCLUSIONS}

It is well known that HEMT devices have a speed advantage over MEsFET devices because of the higher electron mobility in the undoped GaAs layer of the heterostructure than in the doped GaAs of the MESFET. Thus to enable the fabrication of a truly integrated circuit HEMT-type microwave antenna driver to which control and data signals are sent optically it is important that the optical receiver also be fabricated on the chip. The work reported here offers encouragement that such integration is possible. However, the main detector advantage observed to date is a higher coupling efficiency caused by the increased absorption thickness of the GaAs. At this point it is not clear whether there is a speed advantage to be gained by the use of HEMT material for stand-alone detectors.

\section{REFERENCES}

1. Bhasin, K.B., Anzic, G., Kunath, R.R., and Connolly, D.J., "Optical Techniques to Feed and Control GaAs MMIC Modules for Phased Array Antenna Applications," Eleventh AIAA Communications Satellite Systems Conference, AIAA, New York, 1986, pp. 506-513.

2. Slayman, C.W., and Figueroa, L., "Frequency and Pulse Response of a Novel High Speed Interdigital Surface Photoconductor (IDPC)," IEEE Electron Dev. Lett., Vol. 2 , pp. 112-114, 1981 .

3. Roth, W., Schumacher, H., Kluge, J., Geelen, H.J., and Beneking, H., "The DSI-Diode - A Fast Large-Area Optoelectronic Detector," IEEE Trans. Electron Dev., Vol. 32, pp. $1034-1036,1985$.

4. Wojtczuk, S.J., Ballantyne, J.M., Chen, Y.K., and Wanuga, S., "Monolithically Integrated Photoreceiver With Large Gain-Bandwidth Product," Electron. Lett., Vol. 23, pp. $574-576,1987$.

5. Chen, C.Y., Cho, A.Y., Bethea, C.G., Garbinski, P.A., Pang, Y.M., Levine, B.F., and Ogawa, K., "Ultrahigh Speed Modulation-Doped Heterostructure Field-Ef fect Photodetectors," Appl. Phys. Lett., Vol. 42, pp. 1040-1042, 1983.

6. Umeda, T., Cho, Y., and Shibatomi, A., "Picosecond HEMT Photodetector," Jpan. J. Appl. Phys. Lett., Vol. 25, Pp. L801-L803, 1986.

7. Chen, C.Y., Olsson, N.A., Tu, C.W., and P.A. Garbinski, "Monlithic Integrated Receiver Front End Consisting of a Photoconductive Detector and a GaAs Selectively Doped Heterostructure Transistor," Appl. Phys. Lett., Vol. 46, pp. 681-683, 1985. 
ORIGINAL PAGE IS

OE POOR QUALITY

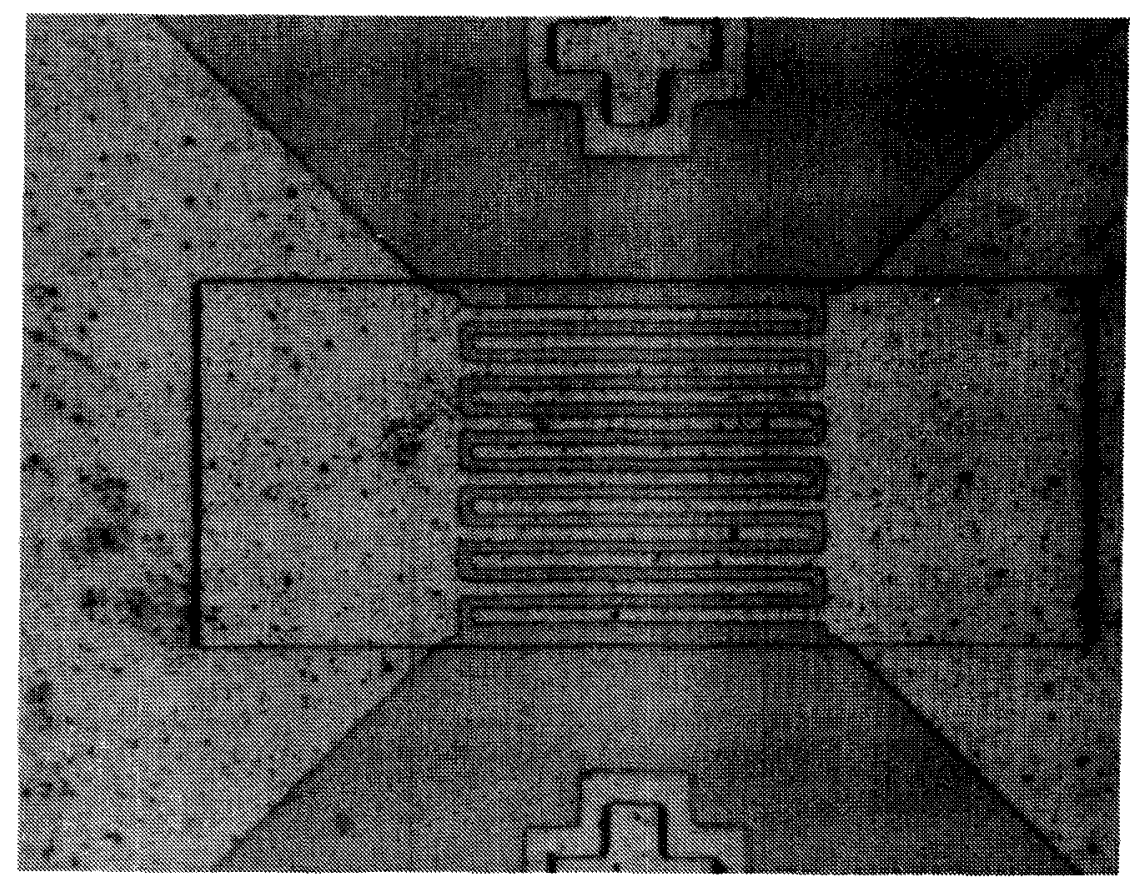

FIGURE 1. - HEMT DETECTOR 5 HM CONTACT SEPARATION.

HEMT PHOTOCONDUCTOR STRUCTURE

\begin{tabular}{|c|c|c|c|}
\hline \multirow[t]{2}{*}{$\begin{array}{c}\mathrm{Au} / \mathrm{Ge} / \mathrm{Ni} \\
\text { OHOMIC CONTACT }\end{array}$} & & \multicolumn{2}{|c|}{$\begin{array}{c}\mathrm{Au} / \mathrm{Ge} / \mathrm{Ni} \\
\text { OHOMIC CONTACT }\end{array}$} \\
\hline & & $\begin{array}{c}\text { GaAs } \\
(\text { SilEx18) }\end{array}$ & $400 \mathrm{~A}$ \\
\hline \multicolumn{3}{|c|}{ GaAlAs (Si2x1Ex18) } & $400 \mathrm{~A}$ \\
\hline \multicolumn{3}{|c|}{ GaAlAs SPACER } & $40 \mathrm{~A}$ \\
\hline \multicolumn{3}{|c|}{$\operatorname{GaAs}(<1 \operatorname{Ex} 15)$} & $12 \mu \mathrm{m}$ \\
\hline \multicolumn{4}{|c|}{ S. I. GaAs } \\
\hline
\end{tabular}

FIGURE 2. - VERTICAL MATERIAL STRUCTURE OF HEMT PHOTOCONDUCTOR. 


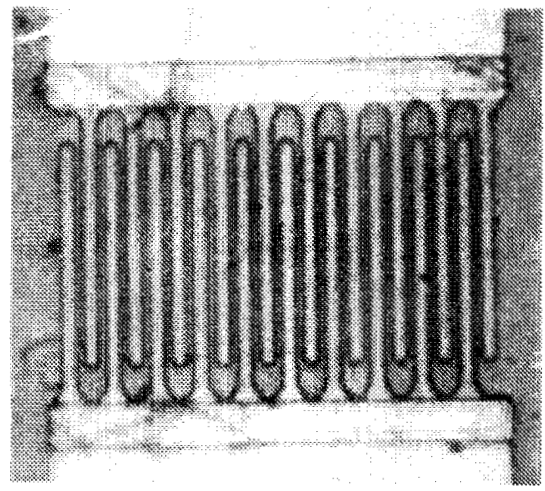

$1 \mu \mathrm{M}$

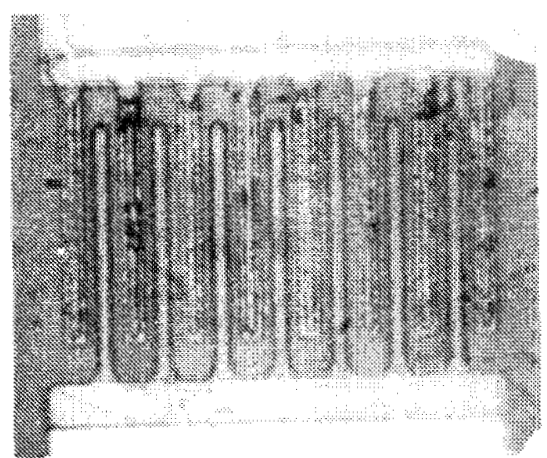

$1.7 \mu \mathrm{M}$

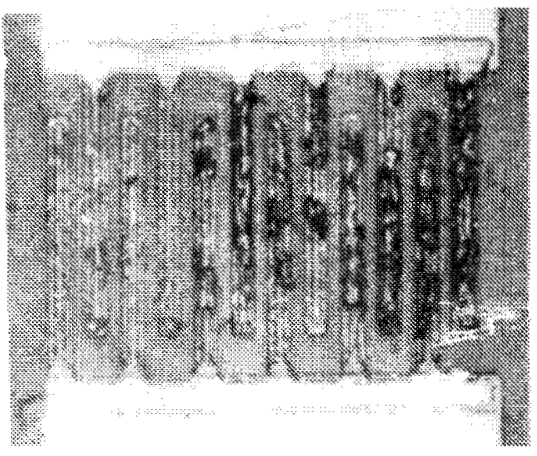

$2 \mu \mathrm{M}$

FIGURE 3. - MESFET DETECTORS SHOWING CONTACT SEPARATION. 


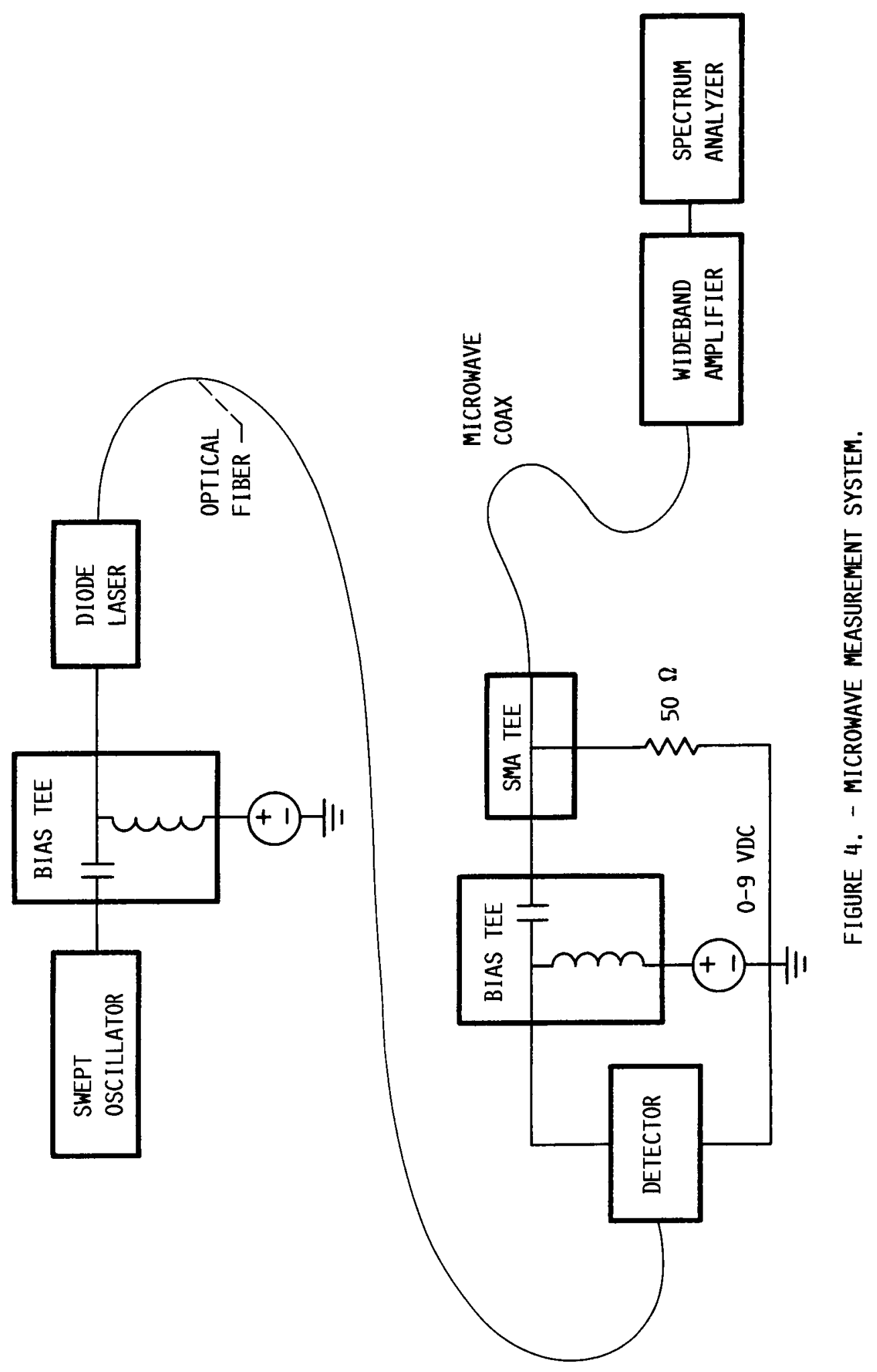


ORIGINAL PAGE IS

OF POOR QUALITY.

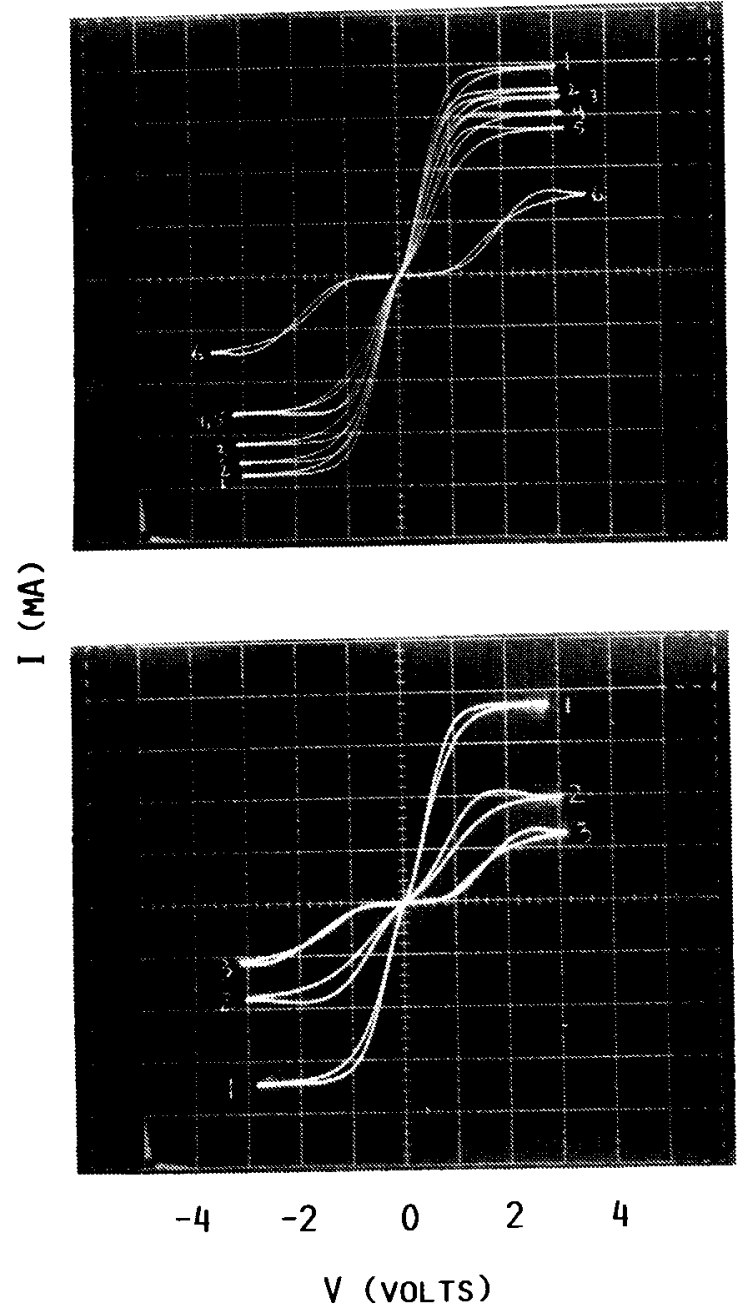

FIGURE 5. - I-V CHARACTERISTIC OF AN HEMT DETECTOR.

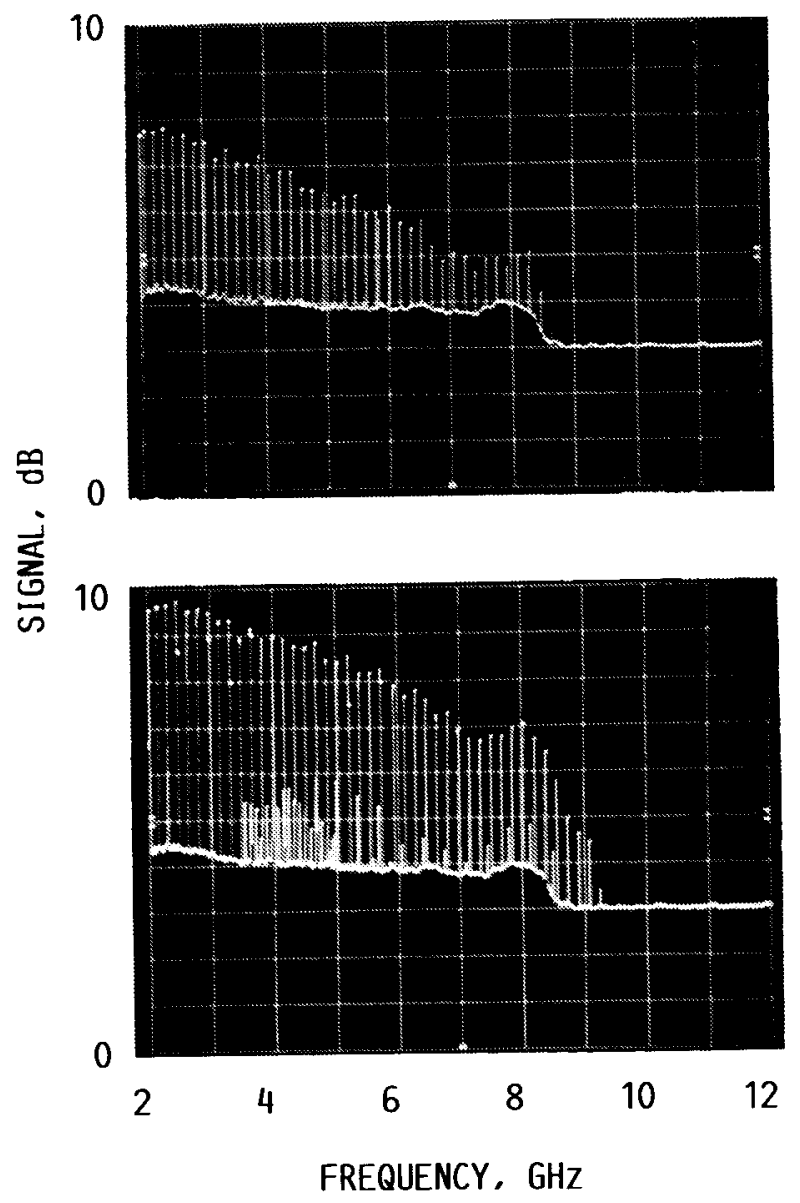

FIGURE 6. - FREQUENCY RESPONSE OF HEMT DETECTOR. 
ORIGINAL PAGE $\mathbf{E}$ OF POOK QUALITY

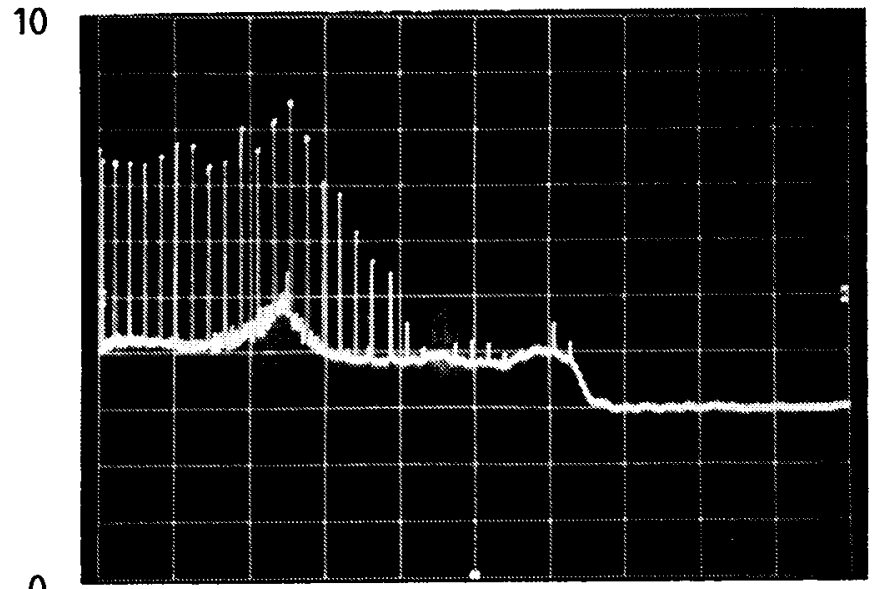

SCHOTTKEY-SCHOTTKEY CONTACTS

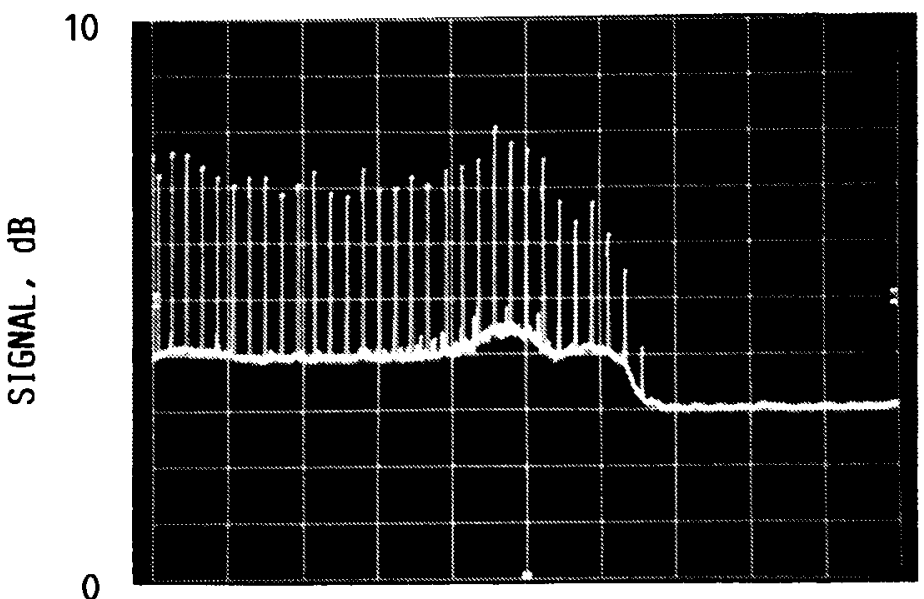

OHMIC-SCHOTTKEY CONTACTS

10

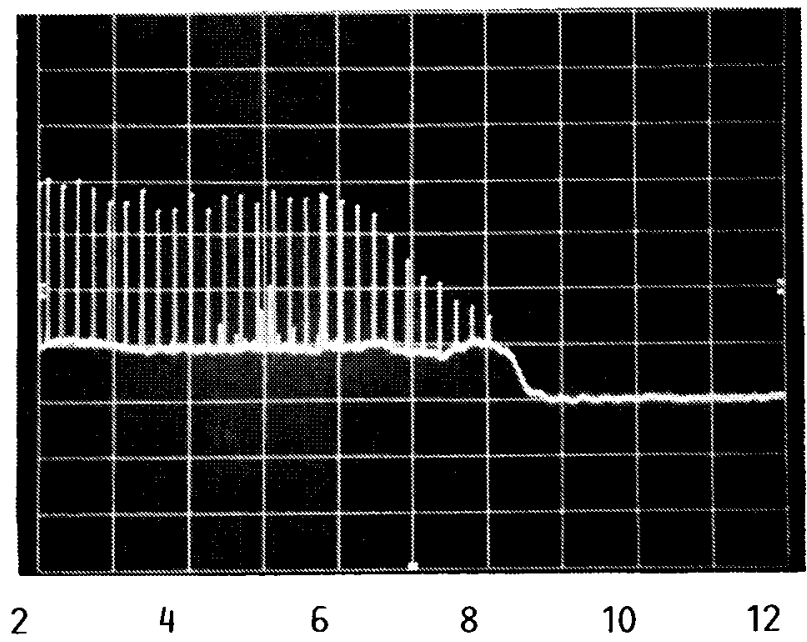

FREQUENCY, GHZ

OHMIC-OHMIC CONTACTS

FIGURE 7. - FREQUENCY RESPONSE OF MESFET DETECTORS. 


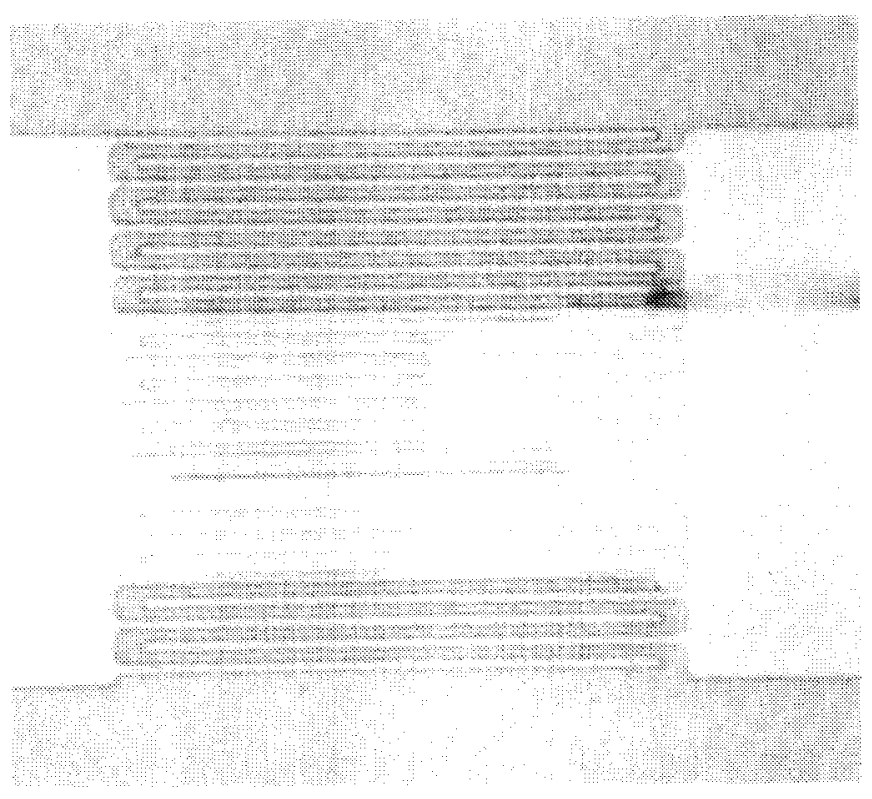

INCOMPLETE PHOTORESIST REMOVAL

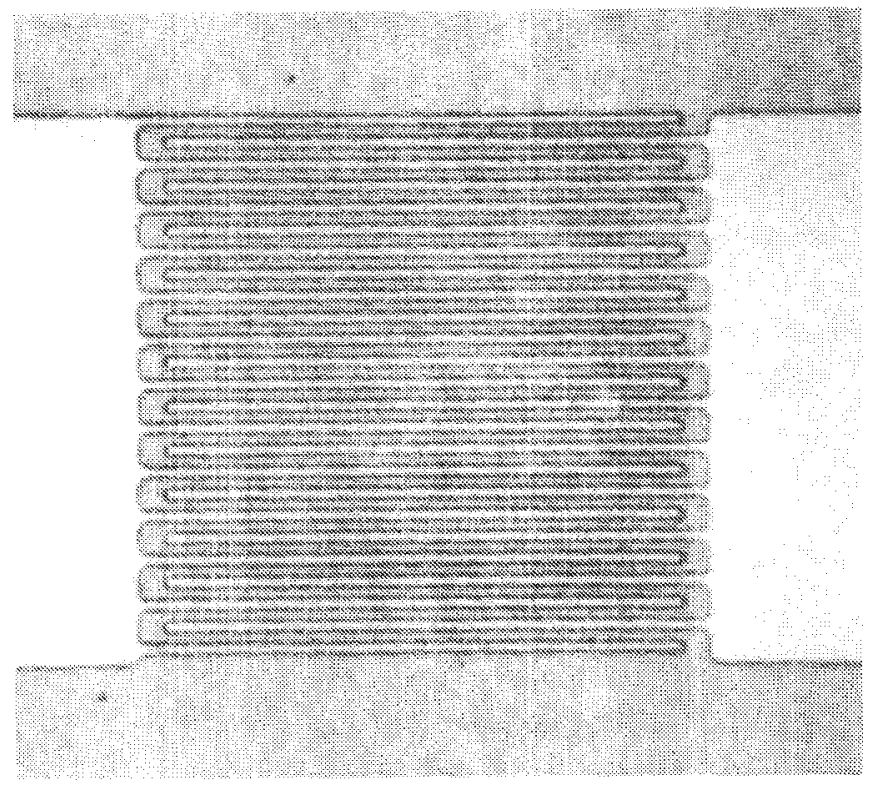

COMPLETE PHOTORESIST REMOVAL

FIGURE 8. - $1 \mu \mathrm{M} \times 1 \mu \mathrm{M}$ STRUCTURE AFTER CONTACT EVAPORATION. 


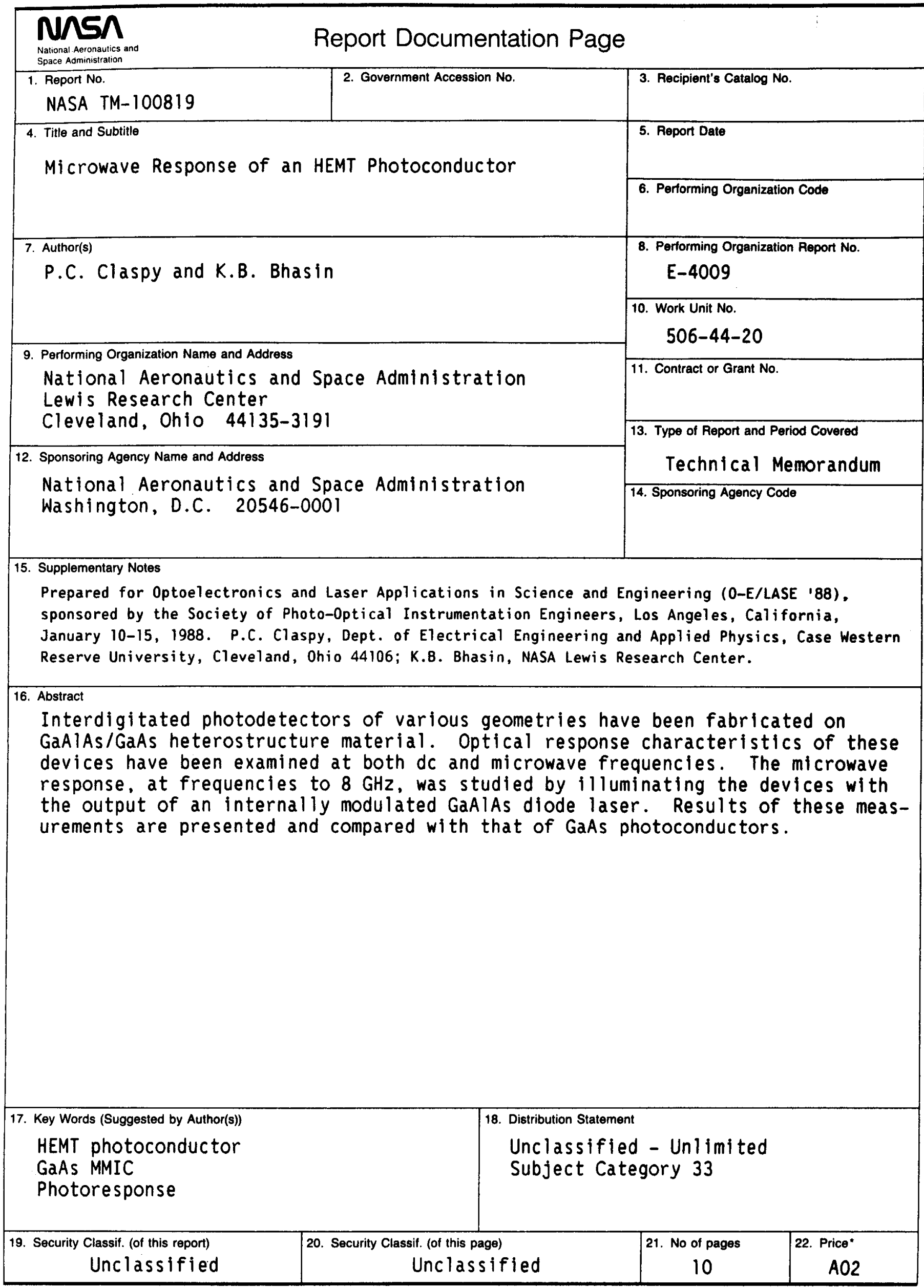

